\title{
Discursos dos professores do apoio educacional especializado sobre inclusão de alunos com transtorno do espectro autista
}

\author{
Amós de Souza Silva \\ Mestre em Ensino pela UNIOESTE \\ Universidade Estadual do Oeste do Paraná \\ 凶amosfoz@gmail.com \\ Paulo Cesar Mayer Morales \\ Pós Doutor em Ensino pela UNIOESTE \\ Docente do Centro Universitário do Maranhão (CEUMA) \\ Maria de Lourdes de Almeida \\ Doutora em Enfermagem pela UFPR \\ Docente da Universidade Estadual do Oeste do Paraná \\ Rosane Meire Munhak da Silva \\ Doutora em Ciências pela EERP/USP \\ Docente da Universidade Estadual do Oeste do Paraná \\ Reinaldo Antonio Silva Sobrinho \\ Doutora em Ciências pela EERP/USP \\ Docente da Universidade Estadual do Oeste do Paraná \\ Adriana Zilly \\ Doutora em Ciências Biológicas pela UEM \\ Docente da Universidade Estadual do Oeste do Paraná
}

Recebido em 3 de outubro de 2018

Aceito em 29 de novembro de 2018

\section{Resumo:}

O autismo é um complexo transtorno neurológico e do desenvolvimento, multifatorial que requer atenção especializada para uma inclusão escolar satisfatória e de qualidade. O papel do professor de apoio educacional é de extrema relevância para o acompanhamento de uma criança autista no que se refere à inclusão escolar. O objetivo do presente estudo foi conhecer os discursos sobre a inclusão de alunos com Transtorno do Espectro Autista, as estratégias utilizadas e as dificuldades apresentadas pelos Professores de Apoio Educacional Especializado do Núcleo Regional de Educação de Foz do Iguaçu, Paraná. Trata-se de um estudo qualitativo, realizado no ano de 2016, tendo como participantes seis professores que foram entrevistados utilizando-se de um questionário semiestruturado, cujas respostas foram analisadas segundo o método do Discurso do Sujeito Coletivo e todos os aspectos éticos respeitados. Como resultados, dificuldades didáticas e questões comportamentais que devem ser trabalhadas foram identificados. Estratégias nas áreas pedagógica e comportamental, formação específica para trabalhar com autismo, descumprimento das leis existentes acerca da inclusão escolar e ausência da família foram dificuldades apresentadas pelos professores para que a inclusão ocorra. Pontua-se a necessidade de melhorar a formação para que os Professores de Apoio Educacional Especializado atendam às dificuldades dos alunos com estratégias e os ajudem a se apropriarem dos conteúdos e a minimizar as dificuldades para a inclusão escolar adequada.

Palavras-chave: Inclusão, Transtorno do Espectro Autista, Educação Especial, Apoio Educacional Especializado. 


\title{
Discourse of teachers of specialized educational support about inclusion of students with autistic spectrum disorders
}

\begin{abstract}
:
Autism is a complex neurodevelopmental, multifactorial disorder that requires specialized attention for satisfactory school inclusion. The teacher of educational support is extremely important for the follow-up of an autistic child, aiming at both school inclusion and learning. The objective of the present study was to know the discourse about the inclusion of students with Autism Spectrum Disorder; identify the strategies and difficulties showed by the Teachers of Specialized Educational Support in the Regional Center of Education of Foz do Iguaçu, Paraná. It is a qualitative study, conducted in 2016, teachers were interviewed using a semi-structured questionnaire. The project was approved by the Ethics Committee. Teacher's speeches were analyzed according to the Discourse of the Collective Subject method. The analysis identified students with didactic and behavioral difficulties that must be worked. Training, noncompliance with the laws about inclusion and non-engagement of the family were difficulties presented for the school inclusion. It's necessary to improve the training so that the Teachers of Specialized Educational Support meet the difficulties of the students with strategies that help them take ownership of the contents and the minimization of the difficulties for the best school inclusion.
\end{abstract}

Keywords: Inclusion, Autistic Disorder, Special education, Remedial Teaching.

\section{Discurso de los profesores del apoyo educacional especializado sobre inclusion de alumnos con transtorno del espectro autista}

\begin{abstract}
Resumen:
El autismo es un trastorno complejo, multifactorial y requiere atención especializada para una inclusión escolar satisfactoria. El papel del profesor de apoyo educativo es importantísimo para el acompañamiento de un niño autista, buscando tanto la inclusión escolar como el aprendizaje. El objetivo fue conocer los discursos sobre la inclusión de alumnos con Trastorno del Espectro del Autismo, las estrategias usadas y las dificultades presentadas por los Profesores de Apoyo Educacional Especializado en el Núcleo Regional de Educación de Foz do Iguaçu, Paraná. Estudio cualitativo, realizado en 2016, seis profesores fueron entrevistados usando un cuestionario semiestructurado. Trabajo aprobado por el Comité de ética. Los testimonios analizados por el Discurso del Sujeto Colectivo apuntaron que los alumnos tienen dificultades didácticas y cuestiones comportamentales que deben ser trabajadas. Estrategias en las áreas pedagógica y conductual, formación específica para trabajar con autismo, incumplimiento de las leyes existentes sobre la inclusión escolar y ausencia de la familia fueron dificultades presentadas por los profesores para que la inclusión ocurra. Es necesario mejorar la formación para que los de los Profesores de Apoyo Educacional Especializado atiendan las dificultades de los alumnos con estrategias que les ayuden a apropiarse de los contenidos ya minimizar las dificultades para la inclusión escolar adecuada.
\end{abstract}

Palabras clave: Propensión (Educación), Transtorno Autístico, Educación especial, Educación compensatoria.

\section{INTRODUÇÃO}

O Manual Diagnóstico e Estatístico de Transtornos Mentais (DSM-5) passou a classificar o Autismo como Transtorno do Espectro Autista (TEA), abrangendo os transtornos Autismo, Síndrome de Asperger, Transtorno Desintegrativo da Infância e Transtorno Global do Desenvolvimento (TGD), sem outra especificação. O TEA possui as 
seguintes características: manifestação precoce dos sintomas; déficits na interação social e comunicação; padrões repetitivos e restritivos de comportamento, atividade ou interesse; funcionamento social clinicamente prejudicado, sempre com padrões de variação de um indivíduo para outro, justificando a noção de "espectro" (APA, 2013).

O Autismo é considerado um transtorno intrigante e de diagnóstico complexo, principalmente devido a sintomas muito similares com outros comprometimentos, tais como déficit intelectual, distúrbios de linguagem, transtorno de déficit de atenção e hiperatividade e transtornos psicóticos (CONSTANTINO; CHARMAN, 2016). Por esse motivo, em muitas situações, a criança com TEA fica muito tempo sem o diagnóstico correto e tem o seu processo de ensino e aprendizagem prejudicados, porém com um diagnóstico precoce e recebendo os recursos adequados, sua escolarização é possível (BOETTGER; LOURENÇO; CAPELLINI, 2013).

Após o diagnóstico, inicia-se o desafio da inclusão escolar do aluno com TEA, a qual deve envolver não apenas o ingresso do aluno no ensino regular, mas sua integração social com colegas e comunidade escolar, bem como garantir o aprendizado dos conteúdos planejados. Para isso, é fundamental a participação do professor acompanhante, porque esse processo deve ser realizado observando-se dois aspectos essenciais: o déficit intelectual e o relacional, e nesse sentido, a participação e o conhecimento do professor definem o foco necessário em uma ou outra área, de acordo com a intensidade do transtorno (RIOS, 2017).

A função de acompanhante educacional foi criada com base na Lei Berenice Piana, 12.764/2012, que estabelece a Política Nacional de Proteção dos Direitos da Pessoa com TEA e assegura que "em caso de comprovada necessidade, a pessoa com TEA terá direito a acompanhante especializado" (BRASIL, 2012).

No estado do Paraná, esse profissional é chamado de Profissional de Apoio Educacional Especializado (PAEE), conforme a instrução normativa 001/2016. A função do PAEE está prevista em um programa mais abrangente do Ministério da Educação e Cultura (MEC): o Atendimento Educacional Especializado (AEE), que envolve professores de apoio para outras áreas da Educação Especial e os professores das Salas de Recursos Multifuncionais (SRM) (PARANÁ, 2004; BRASIL, 2011).

A literatura tem demonstrado dificuldades para o trabalho do PAEE $\mathrm{e}$ consequentemente para que haja inclusão efetiva, já que sua participação é imprescindível 
no processo de aprendizagem de alunos com comprometimento nas áreas intelectual e de desenvolvimento, nas quais se inclui o TEA (GLAT; PLETSCH, 2012; BOETTGER; LOURENÇO; CAPELLINI, 2013; CABRAL; MARIN, 2017). A Lei 12.764/2012, apesar de instituir a atividade, não define as atribuições desses profissionais; a instrução normativa 001/2016 elenca um conjunto de 19 funções, dentre estas o trabalho de forma colaborativa com os professores de diferentes disciplinas para o planejamento, organização e adaptação das atividades de ensino e avaliação, visando ao progresso cognitivo, emocional e social do aluno, fornecer esclarecimentos sobre o aluno atendido para os diferentes profissionais envolvidos na educação, ampliar a autonomia do aluno sem retirá-lo das interações em sala de aula, realizar atividades de orientação às famílias dos alunos atendidos e elaborar relatórios periódicos de suas atividades, resultados e da participação dos demais envolvidos na atividade de ensino (PARANÁ, 2016).

Nessa direção, este trabalho teve como objetivo conhecer os discursos sobre a inclusão de alunos com TEA, as estratégias usadas e as dificuldades apresentadas pelos PAEE no Núcleo Regional de Educação (NRE) de Foz do Iguaçu, Paraná.

\section{METODOLOGIA}

Este estudo, cuja natureza é qualitativa, foi desenvolvido no NRE de Foz do Iguaçu/Paraná que abrange nove municípios na Região Oeste do Paraná: Foz do Iguaçu, Itaipulândia, Matelândia, Medianeira, Missal, Ramilândia, Santa Terezinha de Itaipu, São Miguel do Iguaçu e Serranópolis do Iguaçu, em um total de 76 escolas que atendem os ensinos fundamental e médio (PARANÁ, 2016).

Obteve-se autorização da Secretaria de Estado da Educação do Paraná e aprovação do Comitê de Ética em Pesquisa em Seres Humanos, sob o Parecer número 1.665.147. A coleta de dados foi conduzida após o professor a ser pesquisado receber informações acerca deste estudo, aceitar participar e assinar o Termo de Consentimento Livre e Esclarecido.

Fez-se contato pessoal com a equipe de Educação Especial do NRE a fim de verificar quantos alunos com TEA estavam em sala de aula comum no ano de 2016 e se possuíam o PAEE. Após informes oriundos do NRE, realizou-se contato com as escolas e os sete PAEE. A coleta de dados ocorreu nos meses de agosto a dezembro desse ano por meio de 
entrevista. Foram entrevistados seis PAEE dos alunos diagnosticados com TEA no NRE de Foz do Iguaçu/PR; uma professora recusou-se a participar da pesquisa.

Com relação ao tamanho da amostra e sua representatividade, Minayo (2017) refere que na pesquisa qualitativa a quantidade de pessoas entrevistadas não é tão importante, nem deve ser pensada de forma preconcebida. Para a autora, o mais importante é qualificar a amostra, a fim de justificar o tamanho. Lefèvre e Lefèvre (2012) assinalam que a amostra pesquisada deve ser suficiente para conter as diferentes opiniões da população em questão ao objeto estudado. Se forem escolhidos os participantes potenciais e eles explicitam dada ideia, então o pesquisador pode ter a segurança de que essa ideia está presente no campo pesquisado.

As entrevistas foram realizadas nos locais de trabalho do professor, em ambiente fechado, com a presença apenas do entrevistador e entrevistado, com duração média de 30 minutos. $\mathrm{O}$ entrevistador era do sexo masculino, também professor, primeiro autor deste trabalho e com experiência na condução do processo. Nas entrevistas foi utilizado um roteiro com seis perguntas abertas validadas por três pesquisadores previamente em entrevista piloto, e não havia qualquer tipo de relação entre o entrevistador e o entrevistado em todos os casos.

A análise dos dados da pesquisa foi realizada por meio da técnica do Discurso do Sujeito Coletivo (DSC), idealizada pelos autores Lefrève e Lefrève no final da década de 1990. O DSC é uma metodologia que busca captar a essência das representações sociais, principalmente aquelas intermediadas pela linguística, expressando-as como discurso coletivo (LEFÈVRE; LEFÈVRE, 2012).

Uma vez obtidos os discursos, é preciso tratar esses dados a fim de que possam expressar a voz da coletividade. Quantificar a frequência com que certas partes do texto se fazem presentes no discurso é uma forma de qualificá-lo e classificá-lo (LEFÈVRE, LEFÈVRE, 2012). Para tanto, o DSC possui algumas ferramentas metodológicas: 1 - As Expressões-Chave (ECH); 2 - As Ideias Centrais (ICs); 3 - As Ancoragens (ACs); 4 - O Discurso do Sujeito Coletivo (DSC) propriamente dito. As ECH são trechos selecionados do material verbal dos depoimentos individuais que melhor descrevem seu conteúdo. Na metodologia do DSC, as ACs são utilizadas somente quando são encontradas, no material verbal, marcas discursivas explícitas dessas afirmações genéricas (LEFÈVRE, LEFÈVRE, 2012) e isso não surgiu nos 
resultados da presente pesquisa. Sendo assim utilizaram-se ECH, ICs e os DSC como figuras de linguagem.

Extraíram-se dos depoimentos as ECH, sintetizando-as segundo as ICs e obtendo-se o DSC propriamente dito, propiciando um significativo ganho de qualidade na pesquisa, pois envolvem opinião e ou representação social com base em depoimentos ou outra maneira de expressão verbal (LEFÈVRE, LEFÈVRE, 2014).

\section{RESULTADOS}

Os resultados apontaram que havia sete alunos com TEA matriculados no NRE de Foz do Iguaçu em 2016. Foi realizada a caracterização de seis alunos devido a uma recusa. Essa amostra revela um dos grandes problemas para o estudo do autismo: o número reduzido de alunos em sala de aula.

Tabela 1 - Caracterização dos alunos com TEA matriculados no NRE de Foz do Iguaçu/PR, 2016

\begin{tabular}{|c|c|c|c|c|c|c|}
\hline Variáveis & Aluno 1 & Aluno 2 & Aluno 3 & Aluna 4 & Aluno 5 & Aluno 6 \\
\hline Idade & 13 & 16 & 18 & 15 & 22 & 14 \\
\hline Sexo & M & M & M & $\mathrm{F}$ & M & M \\
\hline Série & $7^{\circ}$ ano & $9^{\circ}$ ano & $3^{\circ}$ ano EM & $7^{\circ}$ ano & EJA/EM & $7^{\circ}$ ano \\
\hline Diagnóstico & $\begin{array}{l}\text { TEA } \\
\text { leve }\end{array}$ & $\begin{array}{l}\text { TEA } \\
\text { leve }\end{array}$ & $\begin{array}{c}\text { TEA } \\
\text { moderado }\end{array}$ & $\begin{array}{l}\text { TEA } \\
\text { leve }\end{array}$ & $\begin{array}{c}\text { TEA } \\
\text { Moderado }\end{array}$ & $\begin{array}{c}\text { TEA } \\
\text { moderado }\end{array}$ \\
\hline Comorbidade & - & - & - & cegueira & - & - \\
\hline Cidade & $\begin{array}{l}\text { Foz do } \\
\text { Iguaçu }\end{array}$ & $\begin{array}{c}\text { Santa } \\
\text { Terezinha }\end{array}$ & São Miguel & $\begin{array}{c}\text { Medianeir } \\
\mathrm{a}\end{array}$ & $\begin{array}{l}\text { Foz do } \\
\text { Iguaçu }\end{array}$ & Medianeira \\
\hline
\end{tabular}

EJA: Ensino de Jovens e Adultos; EM: Ensino Médio; M: Masculino; F: Feminino.

Fonte: Dados da pesquisa; Foz do Iguaçu-PR, 2016. Elaborado pelo Autor

A caracterização dos alunos com TEA matriculados (Tabela 1) mostrou que suas idades variaram entre 13 e 22 anos, encontrando-se um no terceiro ano, três no sétimo, um no nono e um em Ensino de Jovens e Adultos/Ensino Médio. Cinco eram do sexo masculino e um do sexo feminino. De acordo com o laudo dos alunos, três apresentavam grau leve de autismo, três moderados e um com uma comorbidade, a cegueira. No que diz respeito aos 
Discursos dos professores do apoio educacional especializado

sobre inclusão de alunos com transtorno do espectro autista

locais de residências desses alunos, dois eram de Foz do Iguaçu, dois de Medianeira, um de Santa Terezinha e um de São Miguel do Iguaçu.

No que tange à caracterização dos professores (Tabela 2), todos os sete foram contatados; seis concordaram em participar do estudo e foram entrevistados. As idades variaram de 33-55 anos, sendo seis professoras do sexo feminino e um do sexo masculino. Nenhum professor possuía graduação em Educação Especial, e todos especialização nessa área. Apenas uma professora possuía pós-graduação Stricto Sensu, o Programa de Desenvolvimento da Educação (PDE) equivalente ao nível de mestrado para a rede estadual de ensino. Todos possuíam experiência docente (mais de 10 anos) e em média três anos de atuação na Educação Especial.

Tabela 2 - Caracterização dos PAEEs dos alunos com TEA entrevistados do NRE de Foz do Iguaçu/PR, 2016

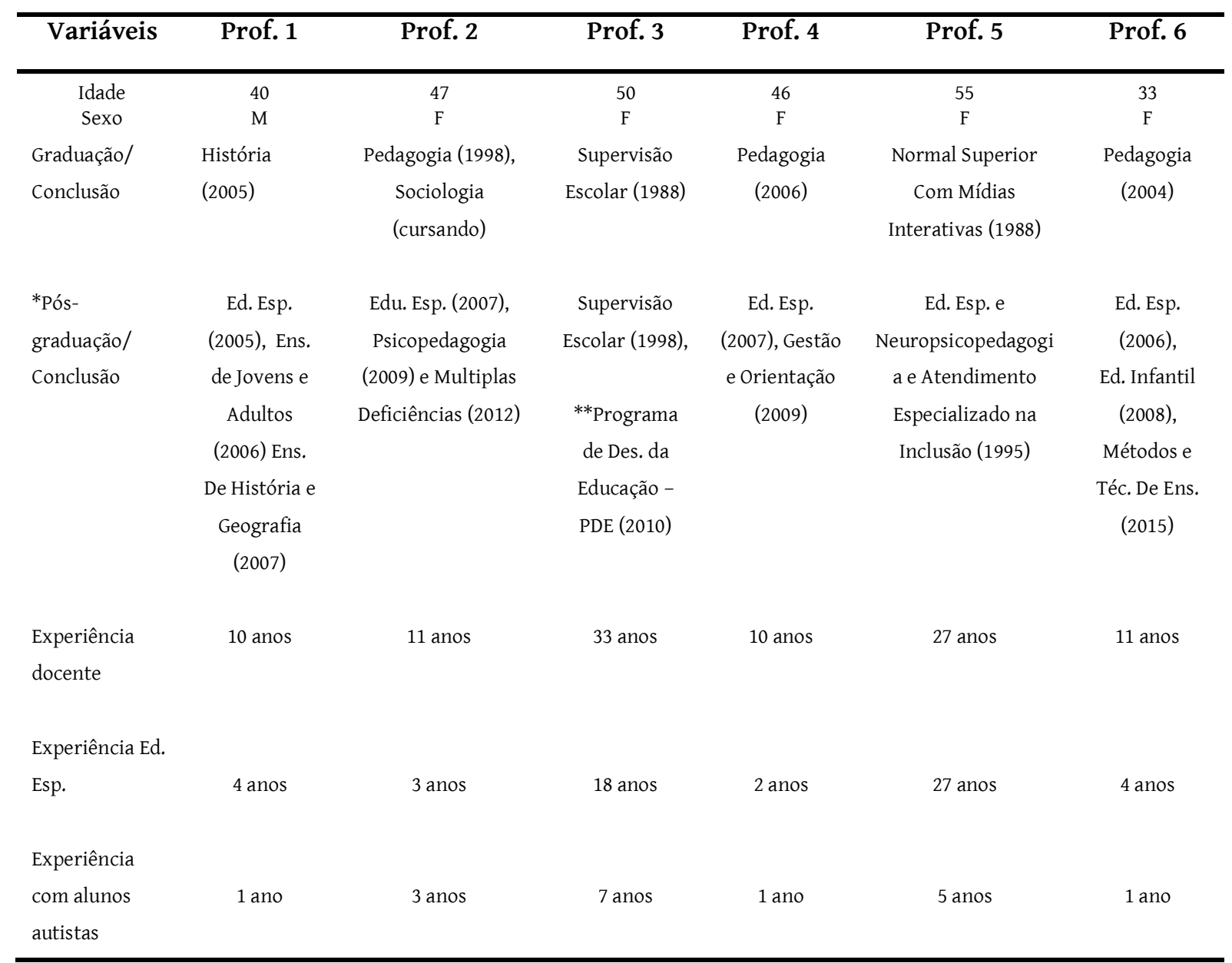

Esp.: especial; Ed.: Educação; Ens.: ensino; Téc. Técnicas; M: Masculino; F: Feminino.

Fonte: Dados da pesquisa. Foz do Iguaçu-PR, 2016.

* Pós-graduações a nível de especialização; ** PDE a nível de mestrado.

Elaborado pelo autor. 
Na sequência, apresenta-se a análise do material coletado nas entrevistas com os PAEE através da técnica do DSC. O Quadro 1 mostra a apresentação geral das questões norteadoras e das ICs que emergiram dos discursos.

Quadro 1 - Panorama geral dos temas que nortearam a entrevista e as Ideias Centrais que emergiram dos discursos dos Professores de Apoio Educacional Especializado

\begin{tabular}{|c|c|}
\hline Tema norteador da entrevista & Ideias Centrais \\
\hline \multirow{3}{*}{$\begin{array}{l}\text { 1. Compreensão do autismo pelo } \\
\text { Professor de Apoio Educacional } \\
\text { Especializado }\end{array}$} & IC1- $O$ autista é aquele que tem dificuldade de socialização \\
\hline & $\begin{array}{l}\text { IC2 - Autista tem características externas peculiares } \\
\text { (estereotipias) }\end{array}$ \\
\hline & IC3 - O autista é quem tem dificuldades de aprendizagem \\
\hline \multirow[t]{2}{*}{$\begin{array}{l}\text { 2. Dificuldades e facilidades } \\
\text { enfrentadas pelo aluno autista }\end{array}$} & $\begin{array}{l}\text { IC4 - As dificuldades são a variação de comportamento e } \\
\text { interpretação de texto }\end{array}$ \\
\hline & IC5 - A facilidade é o rendimento com conteúdos de interesse \\
\hline \multirow{2}{*}{$\begin{array}{l}\text { 3. Estratégias específicas para lidar } \\
\text { com o aluno }\end{array}$} & IC6 - Realização de avaliações diferenciadas \\
\hline & IC7- Negociação e Horário diferenciado \\
\hline \multirow{3}{*}{$\begin{array}{l}\text { 4. Suporte para informações sobre } \\
\text { o autismo }\end{array}$} & IC8 - Rede mundial de computadores \\
\hline & IC9 - Cursos na área \\
\hline & IC10 - Troca de informações \\
\hline \multirow{2}{*}{$\begin{array}{l}\text { 5. Conhecimentos e habilidades } \\
\text { específicas do Professor de Apoio } \\
\text { Educacional Especializado para } \\
\text { lidar com aluno autista }\end{array}$} & IC11 -Conhecimento limitado \\
\hline & IC12- Necessidade de aperfeiçoamento \\
\hline \multirow{2}{*}{$\begin{array}{l}\text { 6. Avaliação da política de inclusão } \\
\text { escolar do aluno autista pelo } \\
\text { Professor de Apoio Educacional } \\
\text { Especializado para lidar com } \\
\text { aluno autista }\end{array}$} & IC13 - Realidade versus proposta \\
\hline & IC14 - Deficiências no atendimento pelo professor e família \\
\hline
\end{tabular}

Fonte: Dados da pesquisa.

Elaborado pelo autor.

A seguir, são apresentados os resultados dos depoimentos dos professores referentes à primeira questão da entrevista, que trata da compreensão do autismo por esse profissional. o Quadro 2 ilustra as ICs e seus discursos correspondentes.

Quadro 2 - Ideias Centrais e Discursos do Sujeito Coletivo referentes à questão: O que você compreende por autismo? Caracterize uma pessoa com autismo

IC1-O autista é aquele que tem dificuldade de socialização
DSC1 - Para mim, o autista é aquele que tem dificuldade no relacionamento com os colegas, tem um mundo diferenciado dos outros e vive aquele mundo, isolado dos demais. O mundo do autista não aceita muito contato, é uma limitação que ele tem de sair do mundo dele para o real. Não consegue formar amizades, é muito fechado e não consegue se socializar; não que seja tímido, isso é da própria deficiência. Tem que ser inserido em meio aos outros alunos, tem que descobrir que aquele é o espaço dele também. A maioria deles 
Discursos dos professores do apoio educacional especializado

sobre inclusão de alunos com transtorno do espectro autista

\begin{tabular}{|l|l|}
\hline $\begin{array}{l}\text { IC2 - Autista tem } \\
\text { características externas } \\
\text { peculiares (estereotipias) }\end{array}$ & $\begin{array}{l}\text { não tem problema de dificuldade de aprendizagem e sim de } \\
\text { socialização. }\end{array}$ \\
\hline $\begin{array}{l}\text { DSC2 - Eu penso que o autista tem características peculiares, eles } \\
\text { balançam as mãos e o corpo, têm mania de carregar objetos com foco } \\
\text { para aquele objeto e de tempos em tempos muda esse foco. Fazem } \\
\text { coisas repetitivas, são quietos e fechados. Seguem uma rotina, não } \\
\text { olham nos olhos. }\end{array}$ \\
$\begin{array}{l}\text { IC3 - O autista é } \\
\text { apren tem dificuldades de }\end{array}$ & $\begin{array}{l}\text { DSC3 - Para mim, o autista é aquele que vai bem no conteúdo que gosta, } \\
\text { mas em outras disciplinas tem uma dificuldade maior. O Asperger tem } \\
\text { dificuldades de aprendizagem, mas não são tão marcantes quanto o } \\
\text { autista. Ele tem dificuldade com matemática, no raciocínio lógico e } \\
\text { interpretação de texto. }\end{array}$ \\
\hline
\end{tabular}

Fonte: Dados da pesquisa.

Elaborado pelo autor.

$\mathrm{Na}$ primeira questão, buscou-se saber como os professores identificam uma pessoa com TEA. A IC1 originou um DSC que descreve questões sobre o relacionamento de alunos com TEA como uma característica observável para identificá-los. A IC2 gerou um DSC que aborda as estereotipias como forma de caracterizar uma pessoa com TEA e o discurso gerado pela IC3 foca na questão da dificuldade de aprendizagem. Essas são, portanto, as três maneiras relatadas pelos professores para identificar uma pessoa com TEA.

O Quadro 3 mostra os resultados da entrevista com os professores referentes à segunda questão, as dificuldades e facilidades apresentadas pelos alunos autista no ambiente escolar.

Quadro 3 - Ideias Centrais e Discursos do Sujeito Coletivo relativas à questão: Quais as maiores dificuldades e facilidades apresentadas por seu aluno autista no ambiente escolar?

\begin{tabular}{|l|l|}
\hline $\begin{array}{l}\text { IC4 -As dificuldades são a } \\
\text { variação de } \\
\text { comportamento e } \\
\text { interpretação de texto }\end{array}$ & $\begin{array}{l}\text { DSC4 - Uma dificuldade é a que o autista é um pouco bipolar, tem dias } \\
\text { que ele não quer ajuda, não pega o caderno, não quer estudar, não quer } \\
\text { contato comigo. Tem dificuldade na interação social, dificuldade de } \\
\text { manter o contato com as pessoas. A aula precisa ser bem organizada } \\
\text { para que ele possa acompanhar, muitos com dificuldades com } \\
\text { interpretação de textos. }\end{array}$ \\
\hline $\begin{array}{l}\text { IC5 - A facilidade é o } \\
\text { rendimento com } \\
\text { conteúdos de interesse }\end{array}$ & $\begin{array}{l}\text { DSC5 - Fica mais fácil para eles quando trabalhamos com disciplinas } \\
\text { que eles gostem. }\end{array}$ \\
\hline
\end{tabular}

Fonte: Dados da pesquisa.

Elaborado pelo autor.

O DSC gerado pela IC4 possui expressões que demonstram um comportamento variável do aluno com TEA e isso é retratado pelos PAEE como uma dificuldade para o ensino, dificuldade de compreender a didática, ou seja, a maneira como o professor expõe e dispõe o conteúdo. Emerge também preá necessidade de entender o modo de o aluno se 
organizar, a adaptação do conteúdo e sua maior dificuldade na área de linguagens. A única facilidade apresentada pelo aluno, exposta pelo DSC da IC5, é quando se trabalha cum conteúdo de seu interesse.

Na sequência da apresentação dos resultados, as ICs e DSC se reportam à questão número três, 'Quais estratégias específicas você utiliza para lidar com este aluno?' (Quadro $4)$.

Quadro 4 - Ideias Centrais e Discursos do Sujeito Coletivo referentes à questão: Quais estratégias específicas você utiliza para lidar com esse aluno?

\begin{tabular}{|l|l|}
\hline $\begin{array}{l}\text { IC6 - Realização de avaliações } \\
\text { diferenciadas }\end{array}$ & $\begin{array}{l}\text { DSC6 - Temos uma avaliação diferenciada para estes alunos, avaliação mais } \\
\text { objetiva e menos extensa, caso contrário ele não consegue. A gente percebe que } \\
\text { tem alguma disciplina que ele está um pouco defasado e que isso vai prejudicá- } \\
\text { lo, então os professores adaptam e fazem uma prova diferenciada, bem fácil. } \\
\text { Alguns fazem avaliação oral. }\end{array}$ \\
\hline $\begin{array}{l}\text { IC7- Negociação e Horário } \\
\text { diferenciado }\end{array}$ & $\begin{array}{l}\text { DSC7 - Identifico o que o aluno mais gosta e então eu faço uma proposta para } \\
\text { ele para trocar algo necessário por algo que ele goste de fazer. Nas disciplinas } \\
\text { em que eles vão mal, eu procuro ajudá-lo a resolver as questões. Às vezes } \\
\text { fazemos para o aluno e assim, ele está prestando atenção e ele aprende. Outra } \\
\text { estratégia é que os professores regentes sempre autorizaram a sair da sala com } \\
\text { ele quando necessário. }\end{array}$ \\
\hline
\end{tabular}

Fonte: Dados da pesquisa.

Elaborado pelo autor.

$\mathrm{Na}$ questão três, buscou-se identificar as estratégias utilizadas pelos professores no dia a dia com o aluno TEA, e gerou duas ICs. A IC6 indica a técnica da avaliação diferenciada como estratégia e a IC7 é relativa ao comportamento do aluno. A primeira relata a "atividade alternativa" (sair de sala, mantê-lo ocupado com atividades extra aula para potencializar o aprendizado), a segunda estratégia relata a técnica da proposta/incentivo, fazer com que o aluno se interesse pelas atividades propostas (Quadro 3).

O Quadro 5 ilustra as ICs e os seus DSC correspondentes que emergiram nos depoimentos da questão número quatro.

Quadro 5 - Ideias Centrais e Discursos do Sujeito Coletivo referentes a questão: Onde ou a quem você recorre quando necessita de informações sobre o autismo? Foz do Iguaçu/PR, 2016

\begin{tabular}{|l|l|}
\hline $\begin{array}{l}\text { IC8 - Rede mundial de } \\
\text { computadores }\end{array}$ & $\begin{array}{l}\text { DSC8 - Eu busco a Internet para pesquisar, pois é mais fácil, é só jogar o } \\
\text { assunto lá e já consigo vários autores, aí a gente vai lendo e vendo o que } \\
\text { tem sobre o assunto. Faço cursos online e procuro em sites do governo } \\
\text { estadual ou federal. }\end{array}$ \\
\hline IC9 - Cursos na área & $\begin{array}{l}\text { DSC9 - Quando tem cursos na área, procuro fazer. Fiz alguns cursos } \\
\text { proporcionados pela Secretaria Estadual de Educação que foram bons, } \\
\text { mas deveria ter mais. Procuro participar porque o professor tem que } \\
\text { estar sempre buscando novos meios de trabalhar com o aluno. }\end{array}$ \\
\hline $\begin{array}{l}\text { IC10 - Troca de } \\
\text { informações }\end{array}$ & $\begin{array}{l}\text { DSC10 - Eu ligo para os professores, converso com a equipe pedagógica, } \\
\text { procuro trocar ideias. Procuramos a escola da modalidade para trazer } \\
\text { um profissional para nos orientar. }\end{array}$ \\
\hline
\end{tabular}

Fonte: Dados da pesquisa.

Elaborado pelo autor. 
$\mathrm{Na}$ pergunta quatro, os professores foram questionados sobre a forma como adquirem conhecimento relativo ao TEA. No DSC da IC8, a resposta foi que o meio mais usado é a Internet. O DSC da IC9 revela que quando é oferecida capacitação, os professores participam, porém declaram que não é suficiente a formação ofertada e expressam a necessidade de se capacitarem. A IC10 produziu um DSC que demonstra a importância do contato entre os professores, a troca de informações, privilegiando principalmente a experiência.

Do material coletado na entrevista com os professores da questão número cinco, emergiram duas ICs e DSCs, apresentadas no Quadro 6.

Quadro 6 - Ideias Centrais e Discursos do Sujeito Coletivo referentes a questão: Você considera seus conhecimentos e habilidades suficientes para lidar com um aluno autista? Gostaria de algum tipo específico de aperfeiçoamento?

\begin{tabular}{|l|l|}
\hline $\begin{array}{l}\text { IC11 - Conhecimento } \\
\text { limitado }\end{array}$ & $\begin{array}{l}\text { DSC11 - Tem muita coisa ainda para aprender e cada caso é um caso. } \\
\text { Nunca é suficiente porque todos os dias eles vêm de uma forma } \\
\text { diferente para a escola. }\end{array}$ \\
\hline $\begin{array}{l}\text { IC12 - Necessidade de } \\
\text { aperfeiçoamento }\end{array}$ & $\begin{array}{l}\text { DSC12 - Os cursos precisam ser mais práticos, tem que coincidir com a } \\
\text { realidade do aluno, trazendo exemplos de como trabalhar com esse } \\
\text { aluno, porque um autista não é igual ao outro. Deveriam ser cursos } \\
\text { relacionados com a rotina, como orientar os professores e o que } \\
\text { acontece no dia a dia mesmo. Os cursos precisam ser ministrados por } \\
\text { professores, a maioria dos cursos foi dado por médicos ou psicólogos, } \\
\text { eles têm outra visão. }\end{array}$ \\
\hline
\end{tabular}

Fonte: Dados da pesquisa.

Elaborado pelo autor.

$\mathrm{Na}$ questão cinco, os PAEE fizeram uma autoavaliação, se consideram seus conhecimentos suficientes para lidar com o aluno com TEA e quais os tipos de aperfeiçoamentos gostariaM. No DSC da IC11, os professores expressaram que seus conhecimentos nunca são suficientes para lidar com esses alunos. Após o reconhecimento da capacidade limitada para lidar com alunos com TEA por parte dos PAEE, surgiu a IC12, gerando um DSC que revela a necessidade de aperfeiçoamento.

Em relação à forma como os professores avaliam a política de inclusão escolar de alunos com TEA no tocante às políticas públicas e se sugerem alguma mudança, surgiram duas ICs e DSC (Quadro 7). 
Quadro 7 - Ideias Centrais e Discursos do Sujeito Coletivo referentes a questão: Enquanto professor, como você avalia a política de inclusão escolar do aluno com autismo? Você considera o processo de inclusão de alunos autistas bem-sucedido? Sugere mudanças?

\begin{tabular}{|l|l|}
\hline $\begin{array}{l}\text { IC13 - Realidade versus } \\
\text { proposta }\end{array}$ & $\begin{array}{l}\text { DSC13 - O aluno tem direito à inclusão, mas o governo coloca barreiras } \\
\text { que a gente não consegue resolver, eles querem que o aluno seja } \\
\text { incluso, mas a gente não tem um suporte para isso, é muita burocracia. } \\
\text { Eles poderiam flexibilizar um pouco mais. A inclusão, até por essas } \\
\text { falhas do governo não está acontecendo. É preciso cumprir a lei. É } \\
\text { perfeito o que tem nos documentos, mas, quando a gente se depara na } \\
\text { escola com a prática a gente encontra muitas dificuldades. }\end{array}$ \\
\hline $\begin{array}{l}\text { IC14 - Deficiências no } \\
\text { atendimento pelo } \\
\text { professor e família }\end{array}$ & $\begin{array}{l}\text { DSC14 - A falta de experiência da equipe, professores sem orientação } \\
\text { adequada, despreparados ou com medo. O atendimento deve ter o } \\
\text { acompanhamento multiprofissional, não só do professor, deve ser } \\
\text { psicológico. Deve-se evitar a rotatividade dos professores. É } \\
\text { fundamental a participação da família, a preparação já começa em casa. }\end{array}$ \\
& $\begin{array}{l}\text { É preciso reforçar tudo o que foi praticado com o aluno na escola. } \\
\text { Quando existem atendimentos extras, como fisioterapia ou reforço } \\
\text { escolar, é preciso ser frequente. Às vezes a família não participa e só } \\
\text { sabe cobrar do professor. }\end{array}$ \\
\hline
\end{tabular}

Fonte: Dados da pesquisa.

Elaborado pelo autor.

Da IC13 originou um DSC que aborda a ineficiência do governo em garantir infraestrutura para essa inclusão. Os professores declaram que no papel está tudo bem elaborado, porém na realidade há muitas dificuldades. Ainda nessa IC, os professores criticam a falta do cumprimento da legislação, um fator dificultador para a inclusão através de expressões como: "é muita burocracia"; "eles (o governo) poderiam flexibilizar um pouco mais" e "é preciso cumprir a lei". A IC14 gerou um DSC que contempla as deficiências no atendimento; são levantadas questões como a falta de experiência da equipe educacional, formação inadequada dos professores, e o trabalho multidisciplinar. Os professores sugerem maior participação da família na vida escolar do aluno.

\section{DISCUSSÃO}

A primeira questão que chama atenção é a pequena incidência de alunos com TEA na população pesquisada, a qual envolve nove cidades e 76 escolas. A incidência ora registrada está abaixo dos dados em nível nacional, ou seja, dois a 10 autistas para cada 10.000 alunos (CDC, 2014), o que pode indicar um subdiagnóstico de TEA na região ou baixa taxa de matriculas desses alunos, ao menos na rede pública de ensino. Dos seis alunos cadastrados, cinco eram do sexo masculino, confirmando o que é relatado na literatura, isto é, a 
prevalência maior de meninos com TEA. O DSM-5 aponta que o transtorno é quatro vezes mais frequente em meninos do que em meninas (APA, 2013).

A faixa etária dos alunos com TEA matriculados na rede de ensino variou de 13 a 22 anos, uma faixa mais elevada do que a estimada para os níveis de ensino em que estavam matriculados, os ensinos fundamental e médio, variando de 10 a 18 anos. Contudo, tal dado é menos preocupante do que o observado por Lima e Laplane (2016), os quais apontam que poucos indivíduos com TEA completam o ensino fundamental.

No que tange aos professores, apesar da experiência em sala de aula, o tempo de docência com alunos diagnosticados com TEA é pequeno em número de anos, o que gera uma experiência restrita com o transtorno, podendo prejudicar o aprendizado desses alunos e o vínculo aluno/professor (CAPELLINI; SHIBUKAWA; RINALDO, 2016; BAUER; CASSETTARI; OLIVEIRA, 2017).

Com respeito à compreensão dos professores sobre uma pessoa com autismo, os dados estão de acordo com o DSM-5, que atribui o déficit na interação social, apresentado no discurso, como uma das principais características observáveis no TEA e também o principal sintoma apontado pelos pais na identificação precoce (APA, 2013).

Nesse contexto, é apresentada uma das ideias mais romantizadas, estigmatizadas e estereotipadas sobre a pessoa com autismo, a de que vive no próprio mundo, inacessível, um pensamento originado ainda quando o autismo era tratado como esquizofrenia (McGUIRE, 2016). Schmidt et al. (2016) observaram que esse pensamento do "mundo inacessível" é resultante de uma formação inicial e continuada deficiente, impactando negativamente o fazer pedagógico em sala de aula.

O isolamento do autista é causado muito mais pela incapacidade nas relações sociais impostas pela sociedade do que patológica. Relacionamentos interpessoais pobres, referentes apenas a questões práticas, com baixo investimento social ou afetivo tendem a fazer com que o autista tenha pouco envolvimento com outras pessoas, levando-o ao isolamento. Isso inicia na família e o acompanha em todas as áreas do viver social (CRUZ, 2014).

As estereotipias motoras apareceram no discurso dos professores entrevistados como uma forma de reconhecer uma pessoa com TEA. Esta é caracterizada por comportamentos padronizados e que se repetem, esse tipo de comportamento é uma das 
marcas do TEA (PORCIUNCULA, 2016). Embora comumente vistas apenas como algo negativo, prejudicial ou como um padrão comportamental a ser eliminado, Barros e Fonte (2016) assinalam que as estereotipias precisam ser compreendidas, pois tratam-se de recursos de linguagem para esses sujeitos.

Outra característica como forma de reconhecer uma pessoa com TEA, identificada no discurso dos professores, foi a dificuldade de aprendizagem. Conforme Gadia (2016), esta se manifesta especialmente na falta de interação e consequente isolamento social, gerando, em um segundo momento, comportamento social impróprio, pobre contato visual e déficit afetivo, impactando fortemente a aquisição da linguagem e a comunicação, que se complementam.

Um estudo realizado por Harris et al. (2015) analisou a aprendizagem em alunos com TEA em relação ao que chamaram de "comportamento inflexível". Nesse caso, a escolha do estímulo correto, mantendo-se o padrão e o planejamento, beneficiou o aluno com TEA, reduzindo seu comportamento inflexível e melhorando a aprendizagem.

O fato de os alunos irem bem apenas no conteúdo que eles gostam, segundo os entrevistados, trata-se do interesse restrito, uma estereotipia presente na criança com TEA, particularmente dentre as que apresentam um nível de comprometimento leve (DIHEL, 2017).

Nos DSC1, DSC2 e DSC3 referentes às facilidades e dificuldades dos alunos observadas no ambiente escolar, observou-se uma variedade de graus de comprometimento entre os alunos. Tal informação é compatível com o esperado para esse transtorno. Na última versão do DSM, o manual de psicodiagnóstico, o autismo foi categorizado como Transtorno devido justamente à pluralidade e amplitude de diferentes níveis e comprometimentos, especificamente em relação à linguagem, interação social e dificuldades comportamentais, podendo envolver déficit intelectual (APA, 2013).

No trabalho de Schmidt et al. (2016), professores relataram notar nos alunos comportamentos de ansiedade, impulsividade e agitação, características que dificultariam a aprendizagem e a interação em sala. A literatura apresenta algumas estratégias e técnicas para aprimorar o comportamento dos alunos com TEA o sentido de melhorar sua socialização. Na revisão de Aguiar, Pereira e Bauman (2017), concluiu-se que a atividade física proporcionou melhora no comportamento dos alunos, nas áreas de estereotipias, desatenção, inadaptação e atitudes antissociais. 
O conhecimento das comorbidades que ocorrem com o TEA também é necessário para entender seu comportamento diverso e a forma de agir. Para exemplificar, segundo Marchezan e Riesgo (2016), uma combinação de TEA com deficiência intelectual pode levar a um agravo do déficit de comunicação e interação social, e combinado com Transtorno de Déficit de Atenção e Hiperatividade (TDAH), o aluno com TEA pode apresentar dificuldades de adaptação; comprometimento social e de linguagem, sobretudo no modo desatento; dificuldade motora e irritação. Outras comorbidades do TEA relacionadas ao ensino são transtorno desafiante opositor, transtornos específicos da aprendizagem (dislexia, discalculia, etc.), transtorno bipolar, transtornos da ansiedade, distúrbio do sono e baixa visão, podendo interferir e agravar os sintomas do transtorno (MAZZONE; VITIELLO, 2016; MARCHEZAN; RIESGO, 2016).

Um ponto frisado por Cabral e Marin (2017) para uma efetiva intervenção no comportamento é a parceria família/escola. Os autores sugerem que pode haver uma cooperação na compreensão do comportamento nos dois contextos e na melhor forma de intervir. A família ainda pode auxiliar preparando o aluno, antecipando sua chegada à sala de aula. Essa iniciativa pode evitar comportamentos citados no discurso, como "tem dias que ele chega e é muito difícil", "ele não quer vir para a escola", "não conversa comigo".

Outra dificuldade dos alunos relatada nos discursos dos entrevistados foi a de acompanhar a sequência didática proposta. Uma possível explicação para essa dificuldade foi proposta por Candemil e Silva (2016) ao relatarem que indivíduos com TEA têm dificuldade em perceber a passagem do tempo e, por isso, todas as atividades precisam ser bem definidas e previsíveis. Na verdade, eles possuem a própria organização; ficam em uma zona de conforto, seguem uma rotina rígida e preferem apenas os conteúdos com os quais possuem afinidade, que foi a facilidade apresentada pelos alunos relatada pelos professores no DSC4.

Portanto, ao reconhecer as dificuldades dos alunos, o PAEE é o agente que buscará diminuí-las a fim de viabilizar sua inclusão. Ainda nos DSC4 e DSC5, o pensamento coletivo dos professores revelou a necessidade de promover o desenvolvimento didático e comportamental visando proporcionar uma participação mais efetiva em sala de aula. Para isso, é fundamental o conhecimento e o uso de estratégias corretas de acordo com a individualidade, bem como o reforço das ações positivas, caso do interesse restrito, como trata-se a seguir. 
No DSC6, os professores citaram a avaliação diferenciada como a principal estratégia usada para a escolarização de alunos com TEA. Quanto ao comportamento, os professores versam sobre uma forma alternativa de retomar o foco do aluno em momentos específicos, como, por exemplo, depois do intervalo. A causa mais documentada e aceita para esse comportamento de inquietação é a combinação de TEA e TDAH, que pode causar significativos déficits comportamentais e sociais (MARCHEZAN; RIESGO, 2016).

A negociação identificada no DSC7 é apontada por Sanini e Bosa (2015) como positiva para o incentivo do aluno TEA. Na acepção das autoras, negociar evita o sentimento de disputa e desafio que as crianças podem apresentar ao buscarem a autonomia, inerente ao desenvolvimento infantil, possibilitando a oportunidade de escolha. Impor sem negociar pode trazer mais desorganização para a criança.

Pressupõe-se que no Brasil sejam pouco usadas as técnicas validadas internacionalmente para ensino de alunos com TEA, tais como Videomodelação, Múltiplos Exemplares, Legendas e Role-Play, todas com bons resultados descritos na literatura. Entretanto, somente o uso de técnicas sem uma compreensão de seus fundamentos, reflexão sobre os objetivos ou definição de metas educacionais resulta apenas em uma forma mecanizada de ensino, que desconsidera a individualidade do aluno (SILVA et al., 2017; RODRIGUES; ALMEIDA, 2018).

Os DSCs relacionados às estratégias dialogam com o discurso da IC3 da primeira questão norteadora, referente às dificuldades de aprendizagem, pois o objetivo do uso das estratégias é proporcionar uma melhor aprendizagem. O foco excessivo na área comportamental vinculada ao TEA faz com que a questão pedagógica seja frequentemente colocada em segundo plano. Diversos estudos enfatizam a necessidade de professores desenvolverem estratégias que realmente promovam a escolarização de alunos TEA na sala de aula regular, bem como a realização de mais estudos relativos ao assunto (NUNES; AZEVEDO; SCHMDIT, 2013; CAPELLINI; SHIBUKAWA; RINALDO, 2016; SCHMDIT et al., 2016; CABRAL; MARIN, 2017).

No que se refere à aquisição de informações acerca do autismo relatada pelos professores no DSC8, a maioria respondeu que utiliza a Internet, que contribui muito para a área da capacitação e formação docente com o uso das Tecnologias de Informação e Comunicação (TIC) e os Recursos Educacionais Abertos (REA), ampliando a oferta de cursos a distância e a possibilidade de utilizar o material disponibilizado nos sites oficiais do governo 
para aprimorar a formação. A quantidade de livros disponíveis na Internet de forma gratuita também é um fator positivo, pois amplia as possibilidades de pesquisa (PROCóPIO, 2017).

O DSC10 evidenciou que uma forma pela qual os professores adquirem conhecimento sobre o TEA é a troca de informações entre colegas, nos remetendo à importância do trabalho colaborativo e a um possível indicativo da falta de treinamentos ou acesso à assistência especializada. $\mathrm{O}$ estudo de Pasian, Mendes, Cia (2017) envolvendo 1220 PAEE, em 20 estados e mais de 150 municípios, demonstrou um retrato da formação continuada pelo Brasil. Apenas $7,5 \%$ dos professores se consideram preparados para lidar com as necessidades especiais específicas de seus alunos.

A baixa expectativa de aprendizagem dos professores pode ser explicada, em parte, por uma vulnerabilidade emocional, gerada pela frustração e desamparo, a qual, por sua vez, produz um sentimento de impotência docente, e ainda devido à imprevisibilidade do comportamento do aluno com TEA, vindo a potencializar o estresse laboral, reconhecido como desencadeador do mau desempenho e diminuindo a autoeficácia (NORONHA; FERNANDES, 2008; SCHMDIT et al., 2016).

Surgiu também no discurso dos professores (DSC11) que estes não se sentem preparados de forma segura para lidar com alunos TEA, o que a literatura tem demonstrado correntemente (SANINI; BOSA, 2015; SCHMIDT, et al., 2016). Os depoimentos ainda trazem o temor antigo de não saber trabalhar com o autista severo quando sua única experiência foi com o Asperger ou TEA moderado, de acordo com a nova nomenclatura, devido ao conhecimento limitado (GLAT; PLETSCH, 2012).

Esse discurso mostra ainda que existe a questão da autoeficácia, que segundo Hoy e Miskel (2015), é a percepção ampla de como alguém reconhece sua capacidade de realizar uma tarefa. Essa é uma qualidade necessária para o trabalho de professores, diretores e pessoal de apoio na educação e qualidade fundamental para a inclusão (DIAS, 2017).

Com relação aos fatores para o desenvolvimento da autoeficácia, os dados salientam a pouca experiência para atuar com aluno com TEA, o que gera o receio presente no discurso. Expressões como: "a gente nunca está 100\% preparado"; "eu sei o mínimo do mínimo"; "tem muita coisa ainda para aprender" e "eu tenho muita dúvida", demonstra essa tendência de baixa autoeficácia na amostra estudada (NUNES; AZEVEDO; SCHMDIT, 2013). 
Os DSC13 e DSC14 expressam como os PAEE veem a inclusão nos aspectos legal e estrutural. A legislação prevê a infraestrutura para que haja a inclusão, como consta no texto da Política Nacional da Educação Especial na Perspectiva a Educação Inclusiva - PNEEPEI/2007 (BRASIL, 2007) e do Decreto 6.571/2008, no artigo 3ㅜ, que normatiza o AEE (LEITE; MARTINS, 2015). O uso de recursos tecnológicos demonstra a eficiência de metodologias usando equipamentos de informática (tablets, notebooks, smartphones e computadores) para melhorar a aprendizagem e a interação dos alunos com TEA (SANTAROSA; CONFORTO, 2015).

Ao relatarem os aspectos legais da inclusão, os professores citam os direitos legais dos alunos, as barreiras encontradas por eles e a burocracia como fatores limitantes para o estabelecimento das metas de inclusão. Bento e Nakamura (2016) ressaltam que a Constituição e várias leis infraconstitucionais dão aos alunos com TEA o direito social fundamental à educação nas escolas regulares, porém frequentemente, para que este seja garantido integralmente, é necessário partir pelas vias judiciais.

Os discursos também enfatizaram a questão da deficiência na estrutura de atendimento. Nesse aspecto, Capellini, Shibukawa e Rinaldo (2016) constataram que poucos professores possuem capacitação no tocante à Educação Especial, tendo apenas o magistério como formação. Nunes, Azevedo e Schmidt (2013) observaram a presença de professores com atitudes segregacionistas, provavelmente devido à falta de formação específica.

Outro ponto relevante no discurso dos entrevistados é no que se refere ao trabalho colaborativo como parte da inclusão do aluno com TEA desde o diagnóstico pela equipe multidisciplinar (GONÇALVES; PEDRUZZI, 2013) e por toda a vida escolar. Esses profissionais constituem-se em fonte de informações importantes sobre esse trabalho, visando a intervenções mais eficientes em educação e comportamentais (GUIMARÃES et. al., 2010). Essa prática é prevista na Lei Berenice Piana ao instituir a bidocência, em que o professor acompanhante e o professor regente devem interagir para proporcionar ao aluno TEA uma formação acadêmica e melhor interação social (BRASIL, 2012).

A participação da família na educação do aluno com TEA faz parte do trabalho colaborativo para sua inclusão; quando isso não ocorre, pode-se ter uma escolarização fragmentada (SILVA, SILVA, 2016). É histórica a participação dos pais na "luta" pelos direitos dos autistas, e ainda hoje nota-se a atuação de grupos de pais a fim de que se faça cumprir a Lei quando se fizer necessário. A Lei 12.764/12, conhecida como "lei do autista", é 
fruto da mobilização constante dos pais e familiares por todo o país e de diversas formas, solicitando sua aprovação, que finalmente reconheceu o autismo como deficiência (NUNES; ORTEGA, 2016).

\section{CONSIDERAÇÕES FINAIS}

A inclusão de alunos com TEA, devido às características de transtorno na área mental, possui situações peculiares, requerendo um grande trabalho de percepção e interpretação subjetiva do comportamento do aluno, para assim, ser traçada a forma correta de intervenção.

A formação superficial dos docentes entrevistados faz com que atitudes básicas como o reconhecimento das características da pessoa com TEA não sejam contempladas pela maioria dos profissionais, que se centralizam nas atitudes estereotipadas dos alunos, fazendo aumentar o preconceito e o foco no manejo comportamental em sala de aula em detrimento da socialização e de um aproveitamento escolar efetivo.

Uma formação de qualidade pode aumentar a expectativa de aprendizagem do aluno com TEA por parte do PAEE, fazendo com que os docentes possam dispensar maior atenção às necessidades afetivas e pedagógicas desse aluno e com isso, utilizar estratégias efetivas que venham de encontro às suas dificuldades e potencialidades.

Sendo o TEA muito diversificado em sua apresentação de acordo com os níveis leve, moderado e severo, as ações relativas às formas de intervenção no comportamento são igualmente diversificadas, necessitando de serem previstas o maior número possível de situações na formação, na graduação ou em forma continuada, objetivando evitar temores e surpresas.

Nota-se que as dificuldades demonstradas pelos professores para a inclusão de alunos com TEA são comumente formação inadequada, não cumprimento das leis, falta de estrutura, falta de apoio maciço à inclusão, ausência da família. A facilidade para trabalhar está sempre condicionada à minimização desses fatores para que ocorra a inclusão escolar. 
Espera-se conhecer cada vez melhor o comportamento dos alunos com TEA e suas particularidades, a fim de transferir esse conhecimento produzido para a formação de professores visando a um trabalho mais efetivo de inclusão.

\section{REFERÊNCIAS}

AGUIAR, R. P.; PEREIRA, F. S.; BAUMAN, C. D. Importância da prática de atividade física para as pessoas com autismo. Journal Health Biol Science. v.5, n 2, p.178-183, 2017. Disponível em: <http://periodicos.unichristus.edu.br/index.php/jhbs/article/view/1147>. Acesso em 02 de outubro de 2018.

AMERICAN PSYCHIATRIC ASSOCIATION: DSM-5 - Manual diagnóstico e estatístico de transtornos mentais, 2013.

BRASIL. Política nacional de educação especial na perspectiva da educação inclusiva. Ministério da Educação/SECADI. Documento elaborado pelo Grupo de Trabalho nomeado pela Portaria Ministerial n 555, de 5 de junho de 2007, prorrogada pela Portaria no 948, de 09 de outubro de 2007. Brasília, DF. Disponível em: http://portal.mec.gov.br/arquivos/

pdf/politicaeducespecial.pdf. Acesso em 29 de outubro de 2016.

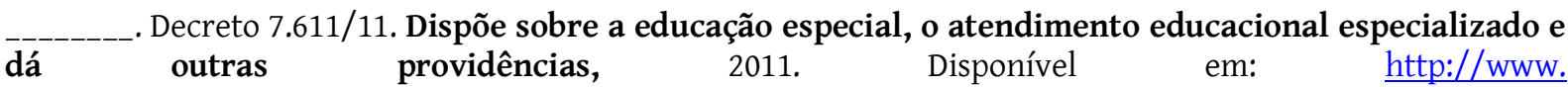
planalto.gov.br/ccivil_03/_ato2011-2014/2011/decreto/d7611.htm. Acesso em 24 de setembro de 2016.

. Lei n 12.764, de 27 de dezembro de 2012. Institui a Política Nacional de Proteção dos Direitos da Pessoa com Transtorno do Espectro Autista. Brasília, 2012. Disponível em: <https://presrepublica.jusbrasil.com.br/legislacao/1033668/lei-12764-12>. Acesso em 27 de maio de 2017.

BARROS, I. B. R; FONTE, R. F. L. Estereotipias motoras e linguagem: aspectos multimodais da negação no autismo. Revista Brasileira de Linguística Aplicada. Belo Horizonte. v. 16, n. 4, p. 745-763, 2016. Disponível em: http://www.scielo.br/scielo.php?pid=S1984-63982016000400745\&script=sci_abstract\&tlng=pt. Acesso em: 01 de outubro de 2018.

BAUER, A.; CASSETTARI N.; OLIVEIRA, R. P. Políticas docentes e qualidade da educação: uma revisão da literatura e indicações de política. Ensaio: aval. pol. públ. Educ., Rio de Janeiro, v.25, n. 97, p. 943-970, 2017.

BENTO, F.; NAKAMURA, S. R. O direito à educação da pessoa com transtorno do espectro do autismo (TEA). Revista Âmbito Jurídico (eletrônica), Rio Grande, XIX, n. 146, 2016. Disponível em: <http://www.ambitojuridico.com.br/site/?n_link=revista_artigos_leitura\&artigo_id=16936>. Acesso em 23 de agosto de 2017.

BOETTGER, A. R. S.; LOURENÇO, A. C.; CAPELLINI, V. L. M. F. o professor de Educação Especial e o processo de ensino-aprendizagem de alunos com autismo. Revista Educação Especial. Santa Maria. v. 26, n. 46. p. 385400, 2013. Disponível em:< https://periodicos.ufsm.br/educacaoespecial/article/view/5833. Acesso em $17 \mathrm{de}$ julho de 2018.

CABRAL, C. S.; MARIN, A. H. Inclusão escolar de crianças com Transtorno do espectro autista: uma revisão sistemática da literatura. Rev. Educ., v. 33, Belo Horizonte 2017 Epub Apr 06, 2017. Disponível em: http://www.scielo.br/scielo.php?pid=S0102-46982017000100113\&script=sci_abstract\&tlng=pt. Acesso em 31 de julho de 2018.

CANDEMIL, L. S.; SILVA, J. V. Jardim en-cantado: material didático para ampliação do repertório musical de alunos com transtorno do espectro autista. In: : BIEGING, P; BUSSARELLO, R. I.; ULBRICHT, V. R. (orgs.) Educação no plural: da sala de aula às tecnologias digitais. São Paulo: Pimenta Cultural, p. 186-200, 2016. 
CAPELLINI, V. L. M. F; SHIBUKAWA, P. H. S.; RINALDO, S. C. O. Práticas pedagógicas colaborativas na alfabetização do aluno com transtorno do espectro autista. Colloquium Humanarum. v. 13, n. 2, p.87-94, abr/jun, $2016 . \quad$ Disponível em: <http://revistas.unoeste.br/revistas/ojs/index.php/ch/article/download/1309/1651>. Acesso em 19 de setembro de 2018.

CENTERS FOR DISEASE CONTROL AND PREVENTION - CDC. 2014. Disponível em: <https://www.cdc.gov/ncbddd/autism/data.html> Acesso em 15 de dezembro de 2017.

CONSTANTINO, J. N.; CHARMAN, T. Diagnosis of autism spectrum disorder: reconciling the syndrome, its diverse origins, and variation in expression. The Lancet Neurology. v. 15, n.3, p. 279-291, 2016.

CRUZ, T. S. U. R.Autismo e Inclusão: experiências no ensino regular. Jundiaí: Paco Editorial, 2014.

DIAS, P. C. A autoeficácia dos professores para a implementação de práticas inclusivas: contributos para uma reflexão sobre a inclusão educativa. Ensaio: Avaliação e Políticas Públicas na Educação (online). v. 25, n. $94, \quad$ p. 7-25, 2017. Disponível em: <http://www.scielo.br/scielo.php?pid=S0104-

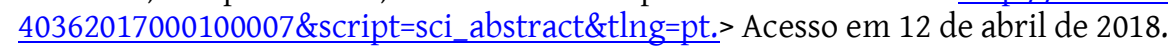

DIHEL, K. Olhando nos olhos: Autismo: Me ame como sou. Porto Alegre: Simplíssimos Livros, 2017.

GADIA, C. Aprendizagem e autismo. In: ROTTA, N. T.; OHLWEILER, L.; RIESGO R. S. (orgs.). In: Transtornos de aprendizagem: abordagem neurobiológica e multidisciplinar. 2 ed. Porto Alegre: Artmed, 2016.

GLAT, R.; PLETSCH, M. D. Inclusão escolar de alunos com necessidades especiais. Rio de Janeiro: EDUERJ, 2012.

GONÇALVES, T. M.; PEDRUZZI, C. M. Levantamento de protocolos e métodos diagnósticos do transtorno autista aplicáveis na clínica fonoaudiológica: uma revisão de literature. Rev. CEFAC. n. 15, v. 4, p. 10111018, jul-ago, 2013. Disponível em: <http://www.scielo.br/scielo.php?pid=S1516-

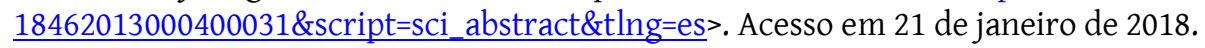

GUIMARÃES, A. L. F.; ALEXANDRE, A. L. A.; TAVEIRA, C. C.; LIMA, C. B; MENDONÇA, K. A. B.; NETTO, M. M. F. C.; D'ACRI, R. S. Orientações para promover a aprendizagem do aluno com Transtornos Globais Do Desenvolvimento (TGD) na sala de aula e na escola. PREFEITURA DA CIDADE DO RIO DE JANEIRO. Secretaria Municipal de Educação. Subsecretaria de Ensino: Coordenadoria de Educação, 2010.

HARRIS, H.; ISRAELI, D.; MINSHEW, N.; BONNEH, Y.; HEEGER, D. J.; BEHRMANN, M.; SAGI, D. Perceptual learning in autism: Over-specificity and possible remedies. Nature. 2015. Disponível em: https://www.nature.com/articles/nn.4129. Acesso em 18 de março de 2018.

HOY, W. K.; MISKEL, C. G. Administração educacional: Teoria, pesquisa e prática. Porto Alegre: AMGH, 2015.

LEFÈVRE, F.; LEFÈVRE, A. M. C. Pesquisa de Representação Social: um enfoque qualiquantitativo. 2 ed., Liber Livro, Brasília, 224 pp., 2012.

LEFÈVRE, F.; LEFÈVRE, A. M. C. Discurso do Sujeito Coletivo: representações sociais e intervenções comunicativas. Revista Texto e Contexto Enfermagem, v. 23, n.2, p. 502-507, 2014. Disponível em: <http://www.scielo.br/pdf/tce/v23n2/pt_0104-0707-tce-23-02-00502.pdf. $>$. Acesso em 07 de dezembro de 2016.

LEITE, L.P.; MARTINS, S. E. S. O. A educação especial em tempos de educação inclusiva: dos aportes normativos aos aspectos operacionais. In: DAVID, C. M.; SILVA, H. M. G.; RIBEIRO, R.; LEMES, S. S. (Orgs.) Desafios contemporâneos da educação. São Paulo: Cultura Acadêmica, p. 85-105, 2015. 
LIMA, S. M.; LAPLANE, A. L. F. Escolarização de Alunos com Autismo. Revista Brasileira de Educação Especial. v. 22, n. 2, p. 269-284, jun, 2016. Disponível em: <http://www.scielo.br/scielo.php?pid=S141365382016000200269\&script=sci_abstract\&tlng=pt.> Acesso em 15 de maio de 2017.

MARCHEZAN, J.; RIESGO, R. S. Comorbidades dos transtornos do espectro autista. In: ROTTA, N. T.; OHLWEILER, L.; RIESGO, R. S. (Orgs.). Transtornos de aprendizagem: abordagem neurobiológica e multidisciplinar. 2 ed. Porto Alegre: Artmed, p. 378-391, 2016.

MAZZONE, L.; VITIELLO, B. Psychiatric Symptoms and comorbidities in autismo spectrum disorder. Switzerland: Springer, 2016.

McGUIRE, A. War on autism: on the cultural logic normative violence. University of Michigan Press, 2016.

MINAYO, M. C. S. Amostragem e saturação em pesquisa qualitativa: consensos e controvérsias. Revista Pesquisa Qualitativa. São Paulo (SP), v. 5, n. 7, p. 01-12, abr., 2017. Disponível em: <http://rpq.revista.sepq.org.br/index.php/rpq/article/view/82>. Acesso em 25 de novembro de 2017.

NORONHA, A. P. P.; FERNANDES, D. C. Estresse laboral: análise da produção científica brasileira na SciELO e BVS-Psi. Fractal: Revista de Psicologia. V. 20, n.2, p. 491-501, 2008.

NUNES, D. R. P.; AZEVEDO, M. Q. O.; SCHMIDT, C. Inclusão educacional de pessoas com Autismo no Brasil: uma revisão da literatura. Revista Educação Especial. Santa Maria. v. 26, n.47. p. 557-572, 2013. Disponível em: https://periodicos.ufsm.br/educacaoespecial/article/view/10178/pdf. Acesso em 26 de agosto de 2017.

NUNES, F.; ORTEGA, F. Ativismo político de pais de autistas no Rio de Janeiro: reflexões sobre o "direito ao tratamento". Revista Saúde Soc. São Paulo, v.25, n.4, p.964-975, 2016. Disponível em: <http://www.scielo.br/scielo.php?pid=S0104-12902016000400964\&script=sciabstract\&tlng=pt>. Acesso em 10 de novembro de 2017.

PARANÁ. Instrução 05/2004: Estabelece para o funcionamento da Sala de Recursos para o ensino fundamental de $5^{\mathbf{a}}$ a $8^{\mathbf{a}}$ séries na área da Deficiência Mental e Distúrbios de Aprendizagem. 2004. Disponível em: http://www.educacao.pr.gov.br/arquivos/File/instrucoes/instrucao0504.pdf. Acesso em 25 de outubro de 2017.

. Seed em números. 2016. Disponível em: <http://www4.pr.gov.br/escolas/numeros/>. Acesso em 28 de maio de 2017.

PASIAN, M. S.; MENDES, E. G.; CIA, F. Atendimento educacional especializado: aspectos da formação do professor. Cadernos de Pesquisa. v.47, n.165, p.964-981, 2017. Disponível em: <http://www.scielo.br/scielo.php?pid=S0100-15742017000300009\&script=sci_abstract\&tlng=pt>. Acesso em 15 de dezembro de 2017.

PORCIUNCULA, R. A. L. Investigação precoce do transtorno do espectro autista: sinais que alertam para a intervenção. In: ROTTA, N. T.; FILHO, C. A. B.; BRIDI, F. R. S. (orgs.). Neurologia e aprendizagem: abordagem muldisciplinar. Porto Alegre: Artmed, 2016.

PROCÓPIO, E. R. Tecnologias e formação de professores: implicações na Educação a Distância. Curitiba: Appris, 2017.

RIOS, C. "Nada sobre nós, sem nós"? O corpo na construção do autista como sujeito social e político. Revista latino-americana Sexualidad, Salud y Sociedad. n. 25, p.212-230, abr., 2017. Disponível em:<http://www.scielo.br/scielo.php?pid=S1984-64872017000100212\&script=sci_abstract\&tlng=pt>. Acesso em 31 de julho de 2018.

RODRIGUES, V.; ALMEIDA, M. A. Modelagem em Vídeo para o Ensino de Habilidades de Comunicação a Indivíduos com Autismo: Revisão de Estudos. Revista Brasileira de Educação Especial. v. 23, n. 4, pp. 595606, 2017. Disponível em: http://www.scielo.br/scielo.php?script=sci_abstract\&pid=S141365382017000400595\&lng=en\&nrm=iso\&tlng=pt. Acesso em 03 de agosto de 2018. 
SANTAROSA, L. M. C.; CONFORTO, D. Tecnologias Móveis na Inclusão Escolar e Digital de Estudantes com Transtornos de Espectro Autista. Rev. Bras. Ed. Esp. Marília, v. 21, n. 4, p. 349-366, 2015. Disponível em: <http://www.scielo.br/scielo.php?pid=S1413-65382015000400349\&script=sci_abstract\&tlng=pt>. Acesso em 16 de novembro de 2017.

SANINI, C;; BOSA, A., C. Autismo e inclusão na educação infantil: Crenças e autoeficácia da educadora. Estudos de Psicologia. v. 20, n. 3, p. 173-183, 2015. Disponível em: <http://www.scielo.br/scielo.php?pid=S1413294X2015000300173\&script=sci_abstract\&tlng=pt>. Acesso em 25 de novembro de 2017.

SCHMIDT, C.; NUNES, D. R. P.; PEREIRA, D. M.; OLIVEIRA V. F.; NUERNBERG, A. H.; KUBASKI, C. Inclusão escolar e autismo: uma análise da percepção docente e práticas pedagógicas. Revista Psicologia: Teoria e Prática. V. 18, n.1, p. 222-235. São Paulo, SP, 2016. Disponível em:<http://pepsic.bvsalud.org/scielo.php?script=sci_arttext\&pid=S1516-36872016000100017>. Acesso em 18 de novembro de 2017.

SILVA, A. J. M.; AMARAL, E. V.; BARBOZA, A. A.; BARROS, R. S. Efeitos do número de exemplares sobre aquisição e generalidade de desempenho em crianças diagnosticadas com transtorno do espectro do autismo (TEA). Revista Brasileira de Análise do Comportamento. vol. 13, n. 1, p. 5-15, 2017. Disponível em: https://periodicos.ufpa.br/index.php/rebac/article/view/5259/4436. Acesso em 01 de agosto de 2018.

SILVA, J. P.; SILVA, P. J. Discente com autismo na sala de aula regular: o que fazer? Research, Society and Development. $\quad$ v. 2, n. 2, p. $\quad 122-135, \quad 2016 . \quad$ Disponível em: <https://dialnet.unirioja.es/servlet/articulo?codigo=6070050>. Acesso em 29 de novembro de 2017.

(cc) Br

Este trabalho está licenciado com uma Licença Creative Commons - Atribuição 4.0 Internacional. 